\title{
Analisis REBA Postur Kerja Operator Lukis Masker Di UMKM Ar- Oemy Collection
}

\author{
Journal homepage : \\ http://journal.UMK.ac.id/index.php/jointech
}

\author{
Vikha Indira Asri, ${ }^{*}$, Akh. Sokhibi ${ }^{2}$, Mia Ajeng Alifiana ${ }^{3}$ \\ ${ }^{1,2}$ Program Studi Teknik Industri, Universitas Muria Kudus, Jl. Lingkar Utara Gondangmanis Bae, 59327, Kudus \\ ${ }^{3}$ Program Studi Manajemen, Universitas Muria Kudus, Jl. Lingkar Utara Gondangmanis Bae, 59327, Kudus \\ * email Koredpondensi : vikha.indira@umk.ac.id
}

\begin{tabular}{l}
\hline INFO ARTIKEL \\
\hline Article history: \\
Received : \\
Accepted : \\
\hline
\end{tabular}

Kata Kunci:

Ergonomic

Potensi Risiko

Reba

\begin{abstract}
ABSTRAK
Masker merupakan salah satu kebutuhan yang sangat diperlukan untuk mencegah penularan Covid19. Permintaan kebutuhan pasar dari masker pada saat pandemic Covid19 ini sangat tinggi. Sehingga banyak produsen masker skala besar Maupun kecil berlomba-lomba untuk memproduksinya. Bahkan terdapat produsen masker dadakan yang dikarenakan jumlah permintaan masker melonjak. UMKM ArOermy Collection Kudus merupakan salah satu produsen masker dadakan, dimana semula memproduksi jilbab dan pakaian muslim. Namun ketika permintahaan masker sangat tinggi, maka memanfaatkan peluang untuk memproduksi masker. Ciri khas dari masker produksi UMKM Ar-Oermy Collection Kudus ini adalah masker lukis. Dimana desain lukis yang terdapat pada masker dilukis langsung oleh operator lukis. Posisi kerja operator lukis pada saat melukis dilakukan diatas meja kecil dan duduk lesehan sehingga sering terjadi keluhan otot pada beberapa bagian tubuhnya. Jika ditinjau dari sikap kerja ergonomi, maka posisi kerja operator lukis tersebut tidak sesuai dengan kaindah-kaidah ergonomi. Adapun metode yang dugunakan dalam penelitian ini adalah metode kuantitatif. Dengan objek penelitian yaitu analisa postur kerja operator lukis masker. Serta alat yang digunakan dalam menganalisa postur kerja menggunakan REBA yang terdapat software ergofellow.

Hasil penelitian menunjukkan nilai skor postur kerja menggunakan REBA adalah 11. Dimana skor 11 ini dapat diartikan postur kerja operator lukis tersebut mempunyai risiko tinggi. Sehingga secepatnya harus dirubah postur kerja nya.
\end{abstract}

\section{PENDAHULUAN}

Postu kerja, merupakan salah satu unsur penting dari sikap kerja yang mengandung resiko tinggi jika dilakukan dengan sikap kerja yang kurang tepat. untuk itu perlu adanya antisipasi agar tidak terjadi kecelakaan kerja maupun penyakit kerja muscoluskelatel disorder. Kesalahan postur kerja tersebut dapat diminimalisir dengan adanya penerapan aspek ergonomi dalam bekerja, baik dari fasilitas kerja maupun metode kerjanya. Dengan kata lain postur kerja yang tidak ergonomis berdampak pada menurunnya produktivitas kerja maupun performa kerja yang dapat mengakibatkan kecelakaan kerja [1].

Musculoskeletal disorders (MSDs) adalah keluhan yang berada pada bagian otot-rangka yang dirasakan oleh seseorang mulai dari keluhan sangat ringan hingga sangat sakit. Keluhan dapat berupa kerusakan pada sendi, ligament, tendon jika otot menerima beban tetap secara terus menerus dan dalam jangka waktu yang lama.[2]. Terdapat diagonis sebesar 11,9\% dan terdapat gejala sebesar $24,7 \%$ pada prevelensi keluhan musculoskeletal disorders (MSDs) di 
Indonesia Prevelensi yang terjadi di Indonesia berdasarkan laporan Riset Kesehatan Dasar pada tahun 2013 [3]. Musculoskeletal disorders (MSDs) sendiri merupakan salah satu factor yang menyebabkan disabilitas terbesar kedua di dunia, dimana penyebab utama nya adalah keluhan pada nyeri punggung [4].

Ar Oemy Collection merupakan salah satu produsen masker kain dimana salah satu produknya adalah masker lukis. Masker tersebut dikerjakan oleh pekerja secara manual. Posisi pengerjaannya dilakukan dengan alas/meja lipat kecil dan hanya duduk bersilah serta tidak memperhatikan aspek ergonomi maupun kesehatan. Sehingga perlu adanya edukasi terkait penerapan posisi kerja yang baik agar tidak menimbulkan cedera di kemudian hari. Penerapan dan Sosialisasi pada pekerja masker lukis Ar Oemy Collection diharapkan mampu memberikan pengetahuan dan pengalaman bagi pekerja agar dapat memperbaiki postur kerja ang mengedepankan aspek ergonomi.

Penelitian terdahulu yang pernah dilakukan terkait analisis postur tubuh dengan metode REBA diantaranya penelitian dengan judul Analisis Potensi Risiko Postur Kerja Pembatik Pada Umkm Muria Batik Kudus [5], penelitian dengan dengan judul Assessment Of Work Posture And Risk Of Musculoskeletal Disorders (Msds) In Floating Chart Fishermen Using Reba Method [6] dan penelitian dengan judul Evaluasi Postur Kerja Pada Umkm Sepatu Dengan Metode Repaid Entire Body Assesment [7]. Gap penelitian dalam penelitian ini adalah perbedaan pada objek peneltiannya.

\section{METODOLOGI PENELITIAN}

Objek penelitian ini adalah analisis postur kerja operator lukis masker di UMKM Ar Oemy Collection Kudus. Metode kuantitatif merupakan metode yang digunakan dalam penelitian ini. Dimana Teknik pengambilan sampel pada umumnya dilakukan secara random, pengumpulan data menggunakan instrumen penelitian, analisis data bersifat kuantitatif/statistik dengan tujuan untuk menguji hipotesis yang telah ditetapkan [8]. Pengambilan Data dilakukan secara langsung dengan mengamati gerakan dan postur kerja operator lukis masker. Kemudian data yang telah diambil dilakukan pengolahan postur kerja dengan analisis REBA yang terdapat pada software Ergofellow. Variabel bebas pada penelitian ini yaitu atribut postur kerja operator lukis masker. Sedangkan variabel terikatnya berupa postur kerja operator luksi masker.

\section{HASIL DAN PEMBAHASAN}

Data postur Kerja operator lukis masker didapatkan dari observasi langsung dan dokumentasi foto pergerakan sikap kerja operator lukis masker. Adapun gambar postur kerja operator lukis masker dan data Assesment REBA dapat dilihat pada gambar 1 dan tabel 1-9 berikut:

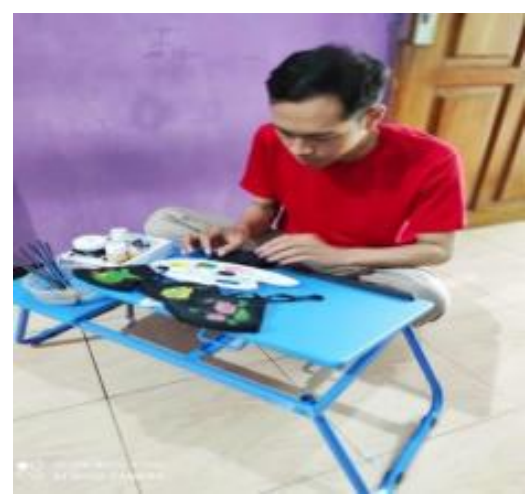

Gambar 1. Postur Kerja Operator Lukis Masker 
Tabel 1. Penilaian Posisi Leher

\begin{tabular}{cc}
\hline Posisi & Hasil \\
\hline tegak & \\
Miring 0 sampai $20^{\circ}$ & \\
Miring 20 $20^{\circ}$ lebih & $\sqrt{ }$ \\
\hline
\end{tabular}

Tabel 2. Penilaian Posisi Batang Tubuh

\begin{tabular}{cc}
\hline Posisi & Hasil \\
\hline tegak & \\
lurus & \\
Miring 0 sampai $20^{\circ}$ & \\
Miring $20^{\circ}$ sampai $60^{\circ}$ & $\sqrt{ }$ \\
Miring $60^{\circ}$ lebih & \\
\hline
\end{tabular}

Tabel 3. Penilaian Posisi Kaki

\begin{tabular}{cc}
\hline Posisi & Hasil \\
\hline Berdiri dengan 2 kaki, berjalan atau duduk & $\sqrt{ }$ \\
Berdiri dengan satu kaki & $\left(\right.$ Kaki ditekuk $\left.>60^{\circ}\right)$ \\
\hline
\end{tabular}

Tabel 4. Penilaian Beban

\begin{tabular}{cc}
\hline Posisi & Hasil \\
\hline Berat kurang dari $5 \mathrm{~kg}$ & $\sqrt{ }$ \\
Berat 5 sampai $10 \mathrm{~kg}$ & \\
Berat lebih dari $10 \mathrm{~kg}$ & \\
\hline
\end{tabular}

Tabel 5. Penilaian Posisi Lengan Atas

\begin{tabular}{cc}
\hline Posisi & Hasil \\
\hline Melebar lebih dari $20^{\circ}$ & \\
Melebar kurang dari $20^{\circ}$ & $\checkmark$ \\
Miring 20 sampai $45^{\circ}$ & $\sqrt{ }$ \\
Miring antara 45 sampai $90^{\circ}$ & \\
Miring lebih dari $90^{\circ}$ & \\
\hline
\end{tabular}

Tabel 6. Penilaian t Posisi Lengan Bawah

\begin{tabular}{cc}
\hline Posisi & Hasil \\
\hline Miring antara 60 sampai $100^{\circ}$ & \\
Miring antara $0^{\circ}$ sampai $60^{\circ}$ atau miring kurang dari & $\sqrt{ }$ \\
$100^{\circ}$ & \\
\hline
\end{tabular}

Tabel 7. Penilaian Posisi Pergelangan Tangan

\begin{tabular}{|c|c|}
\hline Posisi & Hasil \\
\hline $\begin{array}{c}\text { Antara } 15^{\circ} \text { ke atas dan } 15^{\circ} \text { ke bawah } \\
>15^{\circ} \text { ke atas dan } 15^{\circ} \text { ke bawah }\end{array}$ & $\sqrt{ }$ \\
\hline
\end{tabular}


Tabel 8. Penilaian Posisi Coupling

\begin{tabular}{cc}
\hline Posisi & Hasil \\
\hline $\begin{array}{c}\text { Pegangan sesuai dan tidak terlalu kuat } \\
\text { pegangan bisa diterima tapi tidak }\end{array}$ & $\sqrt{ }$ \\
Pegangan tangan memungkinkan tapi tidak bisa \\
diterima
\end{tabular}

Tabel 9. Penilaian Aktivitas

\begin{tabular}{cc}
\hline Posisi & Hasil \\
\hline $\begin{array}{c}\text { Statis selama lebih dari satu menit pada Satu atau } \\
\text { lebih bagian tubuh }\end{array}$ \\
$\begin{array}{c}\text { Lebih dari 4x per menit Aktivitas dilakukan terus } \\
\text { menerus }\end{array}$ \\
$\begin{array}{c}\text { Aktivitas yang terus menerus dan tidak stabil yang } \\
\text { menyebabkan perubahan cepat }\end{array}$ \\
\hline
\end{tabular}

\section{Pembahasan}

Metode REBA merupakan metode yang digunakan dan dikembangkan untuk memberikan penilaian posisi kerja atau postur kerja operator dengan memberikan skoring pada setiap atribut pergerakan bagian tubuh pada saat bekerja. Penilaian ini bertujuan untuk memberikan tingkatan risiko potensi terjadinya musculoskelatel disorder. Sehingga akan memberikan gambaran perbaikan postur kerja untuk kedepannya. Metode ini ditemukan oleh Hignett, S., dan McAtamney, L yang digunakan untuk penilaian aktivitas pada tubuh pekerja secara keseluruhan baik dalam posisi statis ataupun posisi dinamis dengan melakuna pengamatan secara langsung atau dengan video [9]. Hasil penilaian REBA di tunjukkan dengan tingkatan level risiko dan saran perbaikan yang diperlukan kedepannya [10], yaitu:

- Level 1 mempunyai arti tingkat risiko dapat diabaikan dan tidak diperlukan perbaikan

- Level 2-3 mempunyai arti tingkat risiko rendah dan mungkin diperlukan perbaikan

- Level 4-7 mempunyai arti tingkat risiko sedang dan perlu penyelidikan dan perbaikan

- Level 8-10 mempunyai arti tingkat risiko tinggi dan tindakan perbaikan secepatnya

- Level 11-15 mempunyai arti tingkat risiko sangat tinggi dan tindakan perbiakn sesegera mungkin

Gambar berikut adalah hasil analisis metode REBA Posisi Kerja operator lukis masker UMKM Ar Oemy Collectiaon Kudus pada saat melukis dengan menggunakan software ergofellow.

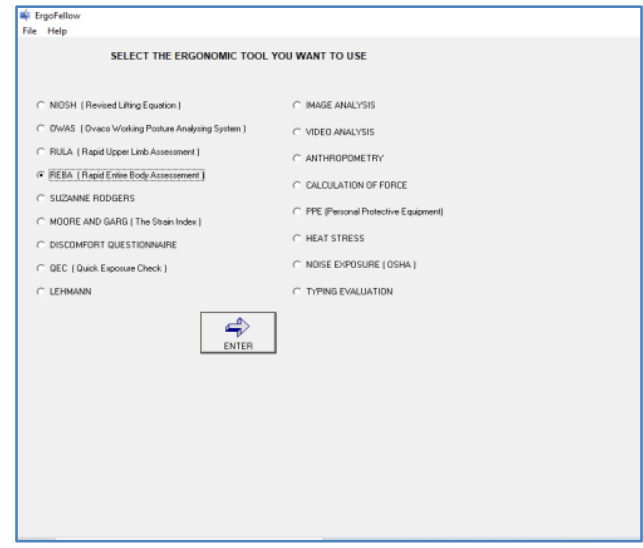

Gambar 2. REBA Anlisis 


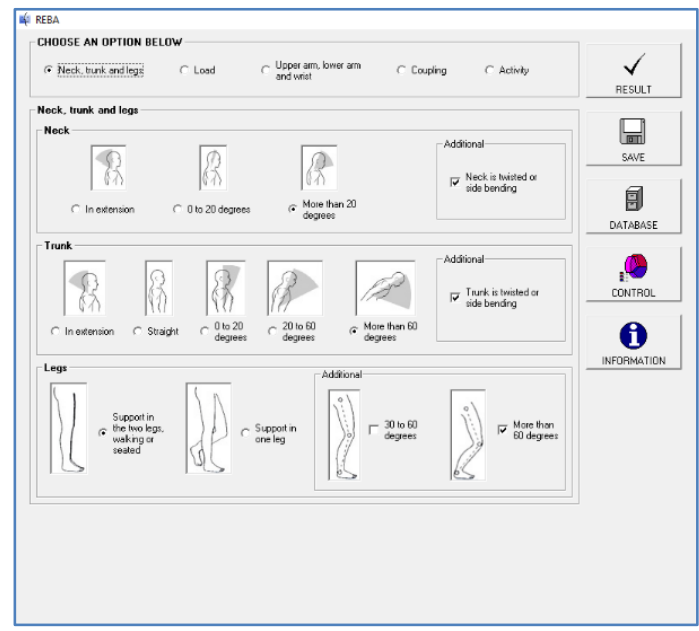

Gambar 3. Penilaian REBA pada Posisi Leher, Batang Tubuh dan Kaki

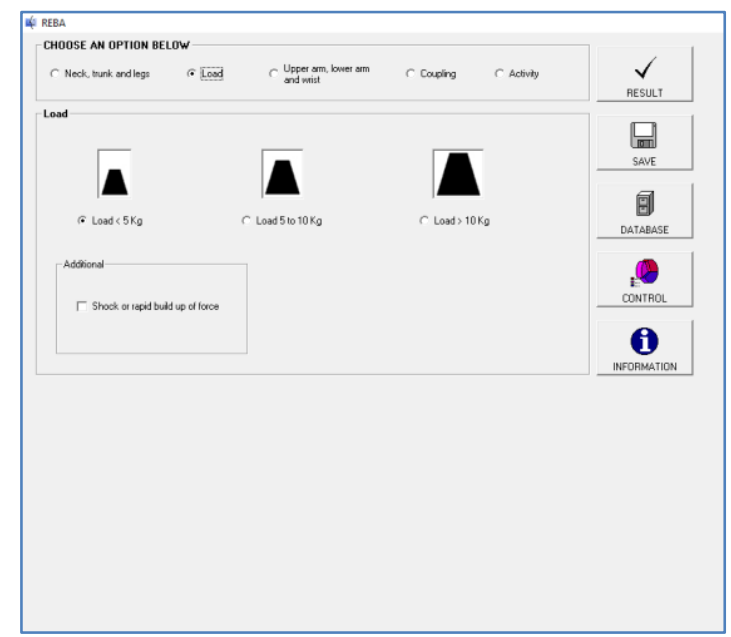

Gambar 4. Penilaian REBA pada Beban

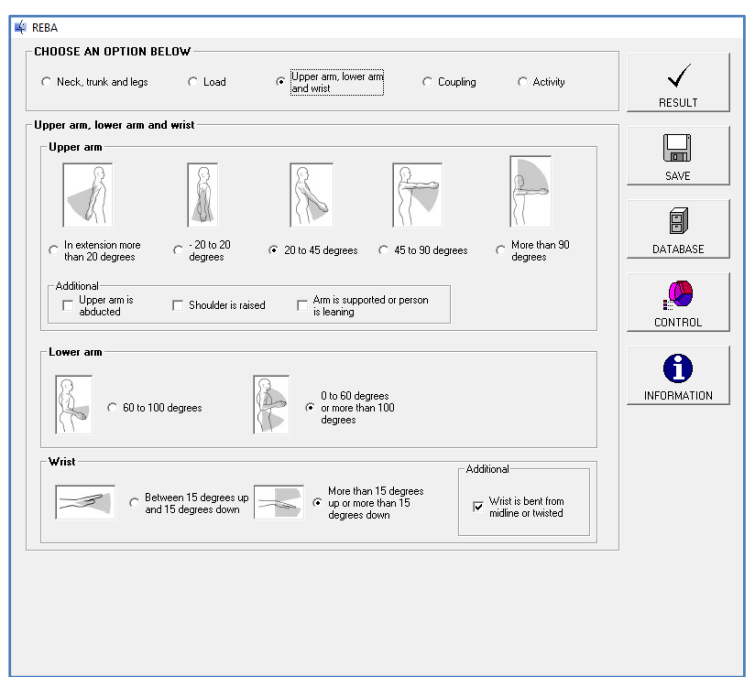

Gambar 5. Penilaian REBA pada Posisi Pergerakan Lengan Atas, Lengan Bawah dan Pergelangan Tangan 


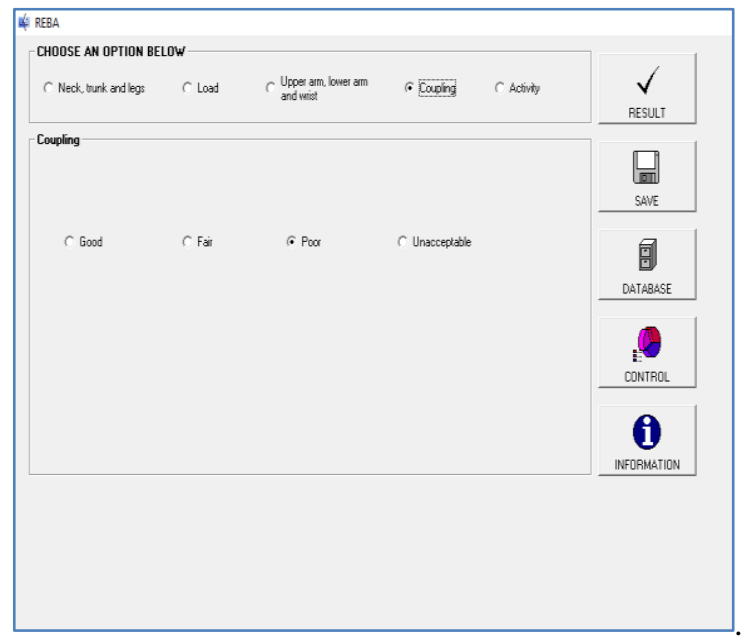

Gambar 6. Penilaian REBA pada Genggaman

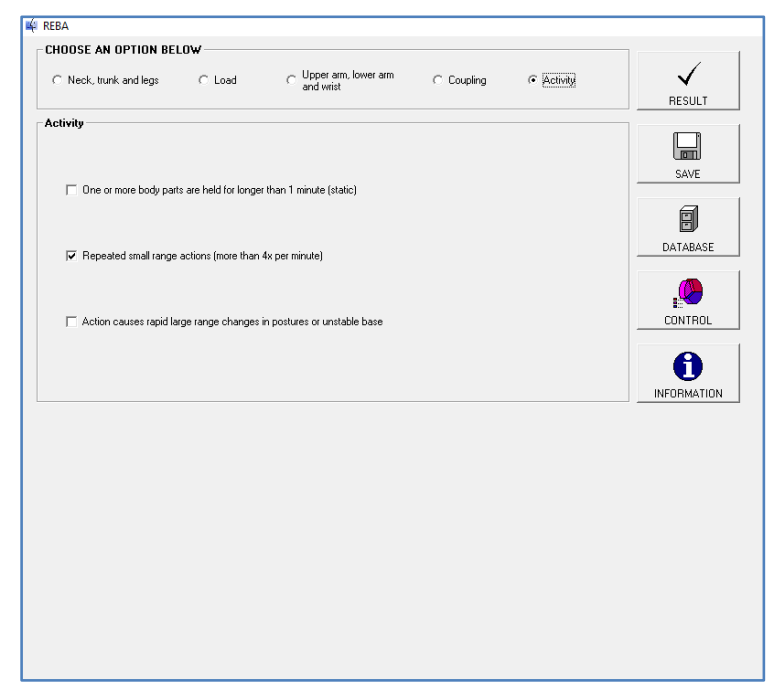

Gambar 7. Penilaian REBA pada Aktivitas

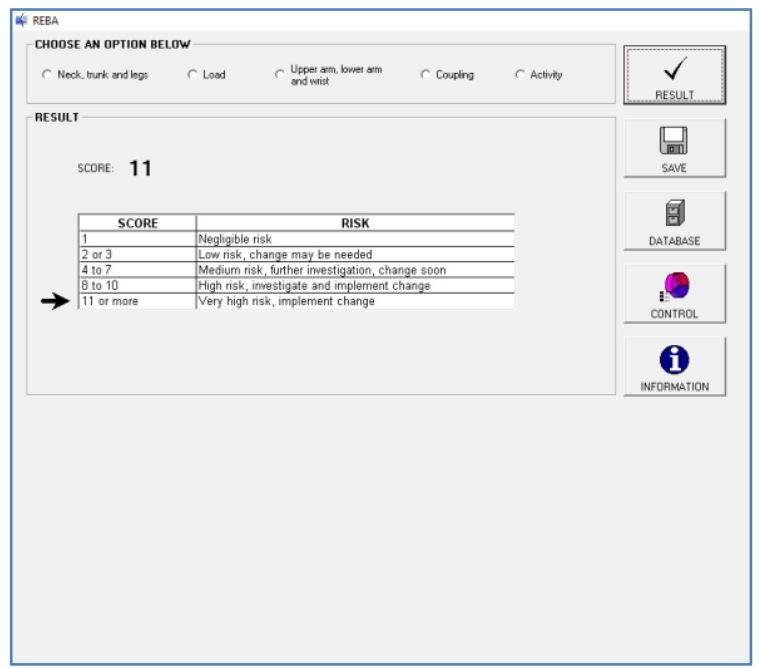

Gambar 8. Hasil Penilaian REBA

Dari gambar 1-8 hasil analisis REBA pada postur kerja operator lukis masker UMKM Ar Oemy Collectiaon Kudus tersebut diatas menunjukkan penilaian dengan skor 11. Dimana 
penilaian dengan skor 11 berada pada tingkatan Level 11-15 yang mempunyai arti tingkat risiko sangat tinggi dan tindakan perbaikan sesegera mungkin pada postur kerja operator lukis masker UMKM Ar Oemy Collection.

Kemudian langkah selanjutnya dengan melakukan analisis potensi risiko pada operator lukis masker UMKM Ar Oemy Collection dengan menemtukan kriteria terlebih dahulu. Kriteria kuantitatif merupakan kriteria yang digunakan dalam menentukan potensi risiko yang terjadi. Adapun data yang digunakan dalam menganalisi potensi risiko adalah data hasil analisis REBA

Tabel 10. Kriteria Potensi Risiko Kuantitatif

\begin{tabular}{lcc}
\hline \multicolumn{1}{c}{ Tingkatan } & Kriteria Kuantitatif & Ket \\
\hline Rendah Sekali & 1 & \\
Rendah & $2-3$ & \\
Sedang & $4-7$ & \\
Tinggi & $10-0$ & \\
Tinggi Sekali & $>11$ & \\
\hline
\end{tabular}

Setelah Kriteria kuantitatif telah ditentukan, maka langkat selanjutnya adalah menghubungkan kriteria kuantitatif tersebut dengan potensi risiko yang dapat dilihat pada tabe1 11 berikut:

Tabel 11. Potensi Risiko Kuantitatif Operator Lukis Masker UMKM Ar Oemy Collectiaon Kudus.

\begin{tabular}{ccccccc}
\hline Postur Kerja & Skor & \multicolumn{5}{c}{ Level Risiko } \\
\cline { 3 - 6 } & REBA & $\begin{array}{c}\text { Rendah } \\
\text { Sekali }\end{array}$ & Rendah & Sedang & Tinggi & $\begin{array}{c}\text { Tinggi } \\
\text { Sekali }\end{array}$ \\
\hline $\begin{array}{c}\text { Operator } \\
\text { Lukis Masker }\end{array}$ & 11 & & & & $\sqrt{ }$ \\
\hline
\end{tabular}

Table 11 diatas, menunjukkan potensi risiko postur kerja pada operator lukis masker UMKM Ar Oemy Collectiaon Kudus pada level tinggi sekali.

\section{KESIMPULAN}

Kesimpulan dari penelitian diatas didapatkan skor nilai analisis postur kerja operator lukis UMKM Ar-Oemy Collection Kudus sebesar 11. Dimana nilai 11 ini mempunyai arti risiko sangat tinggi dan tindakan sesegera mungkin untuk merubah postur kerjanya. Kemudian dari nilai 11 ini dilakukan potensi resikonya. Adapun hasil analisis kuantitatif potensi risiko pada postur kerja operator lukis UMKM Ar-Oemy Collection Kudus pada level potensi risiko yang tinggi sekali.

Saran yang dapat dilakukan kepada UMKM Ar-Oemy Collection Kudus yaitu segera melakukan perubahan fasilitas kepada operator lukis masker berupa meja dan kursi ergonomi.

\section{DAFTAR PUSTAKA}

[1] M. W. Andry Septianto, “Analisa Perbaikan Postur Kerja Pekerja Dalam Ilmu Ergonomi Menggunakan Metode Workplace Ergonomics Risk Assessment (WERA) dan Standard Nordic Questionnaire (SNQ)," Ergon. dan K3, vol. 6, no. 1, 2021.

[2] Tawarka, "Ergonomi Industri. Surakarta: Harapan Press," J. Unair, vol. 3, no. 2, 2010.

[3] A. Ferusgel, A. Anjanny, and D. M. S. Siregar, "Keluhan Musculoskeletal Disorders (MSDs) pada Pekerja Pengguna Komputer Di badan Pusat Statistik Provinsi Sumatera 
Utara," J. Kesehat. Glob., vol. 2, no. 1, 2019, doi: 10.33085/jkg.v2i1.4068.

[4] R. O. Sari, "Hubungan Postur Kerja Dan Masa Kerja Dengan Keluhan Musculoskeletal Disorders (MSDs) Pada Pembatik Giriloyo Di Kabupaten Bantul, Yogyakarta." http://eprints.uad.ac.id/14975/ (accessed May 20, 2021).

[5] M. A. Alifiana, "ANALISIS POTENSI RISIKO POSTUR KERJA PEMBATIK PADA UMKM MURIA BATIK KUDUS,” J. Rekayasa Sist. Ind., vol. 6, no. 2, 2021.

[6] M. F. Yudiardi, "ASSESSMENT OF WORK POSTURE AND RISK OF MUSCULOSKELETAL DISORDERS (MSDS) IN FLOATING CHART FISHERMEN USING REBA METHOD," J. IPTEKS, vol. 8, no. 1, 2021.

[7] R. H. Nasution, "EVALUASI POSTUR KERJA PADA UMKM SEPATU DENGAN METODE REPAID ENTIRE BODY ASSESMENT," Simetris Rekayasa, vol. 2, no. 1, 2020.

[8] P. D. Sugiyono, metode penelitian kuantitatif, kualitatif,dan R\&D. 2016.

[9] L. ignett, S., \& McAtamney, Rapid entire body assessment (REBA). Applied Ergonomics. 2020.

[10] L. and H. S. McAtamney, Rapid entire body assessment In Neville Stanton. et ai Handbook of human Faktors and ergonomis method. USA: CRC Press., 2005. 